\title{
Management of Ectopic Pregnancy at the Brazzaville Hospital and University Centre
}

\author{
Jean Alfred Mbongo ${ }^{*}$, Peggy Mawandza², Gickelle Bitsene Mpika1, Clotaire Itoua1, \\ Léon Herve Iloki ${ }^{1}$
}

${ }^{1}$ Service de Gynécologie Obstétrique CHU Brazzaville, Brazzaville, Congo

${ }^{2}$ Service de Réanimation Polyvalente CHU Brazzaville, Brazzaville, Congo

Email: *mbongojalf@gmail.com

How to cite this paper: Mbongo, J.A. Mawandza, P., Mpika, G.B., Itoua, C. and Iloki, L.H. (2019) Management of Ectopic Pregnancy at the Brazzaville Hospital and University Centre. Open Journal of Obstetrics and Gynecology, 9, 1050-1057. https://doi.org/10.4236/ojog.2019.97102

Received: June 6, 2019

Accepted: July 22, 2019

Published: July 25, 2019

Copyright $\odot 2019$ by author(s) and Scientific Research Publishing Inc. This work is licensed under the Creative Commons Attribution International License (CC BY 4.0).

http://creativecommons.org/licenses/by/4.0/ c) (i) Open Access

\begin{abstract}
Objective: To evaluate the current management of ectopic pregnancies (EPG) at the University Hospital Centre (UHC) in Brazzaville because the practice was usually limited to total salpingectomy by laparotomy. Patients and methods: This was a descriptive study, with retrospective data collection, conducted from July 30, 2015 to January 30, 2016. It included patient records admitted to the Obstetrical Gynecology Department of the Brazzaville University Hospital for an EP, a diagnosis made before visualization on ultrasound of an active embryo outside the uterine cavity or per laparoscopy, but often by exploratory laparotomy. Sociodemographic and clinical data, as well as the therapeutic modalities of the patients, were analyzed. Cases of women operated for EP in other health facilities and referred to the UHC for complication management and cases that were unusable were excluded. Results: We noted 39 EPs out of 4490 deliveries, representing a frequency of $0.86 \%$. The average age of the patients was 28.9 years (extreme 18 - 46 years). The transfusion of labile blood products concerned $84.6 \%$ of patients. There was no therapeutic abstention; medical treatment was performed in 3 patients ( $7.7 \%$ of cases). Diagnostic and therapeutic laparoscopy was performed in 9 patients $(23.1 \%)$ and laparotomy was used in 26 patients (66.7\% of cases) in which 35 Salpingectomies $(89.7 \%$ of cases) were performed. The immediate postoperative period was marked by anaemia (32 cases or $82.1 \%$ ), surgical site infection (1 case or $2.6 \%$ ) and parietal suppuration (1 case or 2.6\%). Conclusion: The dissemination of therapeutic advances in the management of EP is also possible in African settings.
\end{abstract}

\section{Keywords}

EP, Frequency, Therapeutic Modalities, Brazzaville

\section{Introduction}

The incidence of ectopic pregnancy (EP) in developed countries is estimated at 
$2 \%$ of births. The increase in sexually transmitted diseases, their tubal sequelae, the delay in the age of first pregnancy and, above all, the improvement of diagnostic methods that make it possible to recognize an EP with few symptoms are criminalized [1].

In Africa, no national studies have been carried out; the reported incidences only concern hospital studies with frequencies higher than those of developed countries, ranging from $3.15 \%$ to $5.28 \%$ depending on the country [2] [3] [4] [5]. The frequency of EP constitutes a public health problem, its severity: an obstetrical emergency, involving maternal life prognosis for severe bleeding and its sequelae: a fertility problem for women. There are several factors that delay diagnosis: poverty of the population, low level of education, low attendance rates at health facilities and low literacy rates [6] [7].

In Congo, according to previous studies conducted in the same department, the EP was still a major concern. While in the West, therapeutic abstention can be considered [8], and medical treatment and coelio-surgery are the best means of managing EP [9] [10], our practice was limited to total salpingectomy by laparotomy [3]. In view of the impact of this pathology on maternal morbidity and fertility, considering therapeutic advances, it seems appropriate to us to conduct a study whose objective will be to elucidate the current management of IUGs at the University Hospital Centre (UHC) in Brazzaville.

\section{Patients and Methods}

This was a descriptive study, with retrospective recruitment over a six-month period from July 30, 2015 to January 30, 2016. It was conducted in the Department of Gynecology and Obstetrics at the University Hospital of Brazzaville.

Included were the files of women received in gynaeco-obstetrical emergencies and with an EP.

Cases of women operated for EP in other health facilities and referred to the UHC for complication management and cases that were unusable were excluded.

The diagnosis of EP was alerted in front of clinical signs, synthetic culdo or para-synthesis and confirmed by visualization on ultrasound of an active embryo outside the uterine cavity or per laparoscopy, but often by exploratory laparotomy.

We conducted a consecutive and nonprobability sampling.

The variables studied were epidemiological, the location of the EP, and the type of treatment adopted.

\section{Statistical Analysis}

The data were analyzed using Stata software, version 14 .

\section{Results}

We noted 39 EPGs out of 4490 deliveries, i.e. an incidence of 2 EPGs for 230 de- 
liveries. The average age of the patients was 28.9 years (extreme 18 - 46 years). In terms of epidemiology, these patients were poorly educated, single and pauci-geste (Table 1).

Table 2 shows that these were often patients who came on their own in gynaecological emergencies; with the reason of amenorrhea, often associated with pelvic pain. Sometimes, to support the diagnosis, a pelvic ultrasound was performed, and sometimes the dosage of plasma beta-hcg and laparoscopy was necessary. The EP was tubal in 36 patients ( $92.3 \%$ of cases). The directory of seats was noted: ampulla $36 / 39$ (92.3\% of cases), isthmic $4 / 39$ (10.3\% of cases), interstitial $1 / 39$ (2.6\% of cases), infundibular $1 / 39$ (2.6\% of cases). The tubal location concerned the left fallopian tube in 22 patients (56.4\% of cases), the left fallopian tube in 17 patients (43.6\%) and heterotopic in 1 case (2.6\%). In 3 cases (7.7\%), it was an abdominal pregnancy. The gestational age at the time of onset of the EP was 5 weeks in 1 case (2.7\%), 6 to 8 weeks in 8 patients (20.5\%) and 9 to 12 weeks in 30 patients ( $76.9 \%$ of cases) respectively.

In most cases, the clinical signs of the EP were obvious, the latero-uterine mass was found in $59 \%$ of cases. Blood loss was estimated at less than $500 \mathrm{ml}$ in 19 patients (48.7\%), (500\%) $1990 \mathrm{ml}$ in 17 patients (43.6\%) and greater than 200 $\mathrm{ml}$ in 3 patients $(7.7 \%)$. Pelvic adhesions were found in 4 patients $(10.3 \%$ of cases).

For management, $84.6 \%$ of patients received blood transfusion, there were no cases of abstention from therapy, medical treatment was performed in $7.7 \%$ of cases. Laparotomy was used in $66.7 \%$ of cases and in $89.7 \%$ of cases Salpingectomy was performed (Table 3).

Table 1. Patient characteristics.

\begin{tabular}{|c|c|c|c|}
\hline & & $\mathrm{N}=39$ & $\%$ \\
\hline \multicolumn{4}{|c|}{ Le level of study } \\
\hline - & Primary school & 26 & 66.7 \\
\hline- & Secondary & 7 & 17.9 \\
\hline - & Superior & 6 & 15.4 \\
\hline \multicolumn{4}{|c|}{ M Marital Status } \\
\hline - & Married & 15 & 38.5 \\
\hline - & Single & 22 & 56.4 \\
\hline- & Marital life & 2 & 5.1 \\
\hline \multicolumn{4}{|c|}{ Managed } \\
\hline- & Nulligest & 3 & 38.4 \\
\hline - & Small gesture & 23 & 51.3 \\
\hline - & Multigeste & 13 & 10.3 \\
\hline \multicolumn{4}{|c|}{ Parity } \\
\hline - & Nullipare & 15 & 38.4 \\
\hline - & Poor & 20 & 51.3 \\
\hline- & Multipare & 4 & 10.3 \\
\hline
\end{tabular}


Table 2. Diagnostic aspects.

\begin{tabular}{|c|c|c|}
\hline & $\mathrm{N}=39$ & $\%$ \\
\hline \multicolumn{3}{|c|}{ Ad Transmission method } \\
\hline - $\quad$ Referred & 9 & 23.1 \\
\hline Coming from herself & 30 & 76.9 \\
\hline \multicolumn{3}{|c|}{ Cli Clinical signs } \\
\hline - Amenorrhoea & 39 & 100 \\
\hline - P-Pelvic pain & 25 & 64.1 \\
\hline - $\quad$ Metrorrhagia & 16 & 41 \\
\hline \multicolumn{3}{|c|}{$\mathrm{Pa}$ Paraclinical examinations } \\
\hline - $\quad$ L-Laparoscopy & 9 & 23.1 \\
\hline - Ultrasound scan & 20 & 51.3 \\
\hline - $\quad$ Beta hcg plasma & 14 & 35.9 \\
\hline
\end{tabular}

Table 3. Management of the EP.

\begin{tabular}{|c|c|c|c|}
\hline & & $\mathrm{N}=39$ & $\%$ \\
\hline \multicolumn{4}{|c|}{ Medical treatment } \\
\hline- & Methotrexate & 3 & 7.7 \\
\hline- & Blood transfusion & 33 & 84.6 \\
\hline- & S-Surgical treatment & 36 & 92.3 \\
\hline \multicolumn{4}{|c|}{ Ty Type of anaesthesia } \\
\hline- & General anaesthesia & 31 & 79.5 \\
\hline- & Loco-regional anaesthesia & 5 & 12.8 \\
\hline \multicolumn{4}{|c|}{ Su Surgical approach } \\
\hline- & L-Laparoscopy & 9 & 23.1 \\
\hline- & L-Laparotomy & 26 & 66.7 \\
\hline \multicolumn{4}{|c|}{ Su Surgical action } \\
\hline- & S-Salpingectomy & 35 & 89.7 \\
\hline - & Annexectomy & 1 & 2.6 \\
\hline
\end{tabular}

The immediate postoperative period was marked by anaemia (32 cases or $82.1 \%$ ), surgical site infection ( 1 case or $2.6 \%$ ) and parietal suppuration (1 case or $2.6 \%$ ). The average length of hospitalization was 4 days, with no cases of maternal mortality per EP reported. Martial treatment in most cases continued orally externally with a rapid improvement in hemoglobin levels.

\section{Discussion}

The age of onset of EP is similar to the literature, with an average age of 26 to 30 years [11] [12]. However, if the primacy of pauci parity is already reported by 
Dohbit [12], this contradicts some data in the literature [11]. The duration of our study was only six months, with only 39 cases collected this may be a bias in this study. However, in the literature there is credible work, with a long study period, but a relatively small number of cases [13]. Incidence of EPs that we have identified is lower than that of developed countries estimated at 2 EPs per 100 births [1], the delay in the age of first pregnancy leaving time for the development of a tubal disease and especially the improvement of diagnostic methods would be the cause.

In more than half of the cases, to make our diagnosis, we needed ultrasound, but we did not perform any Doppler ultrasound. Some authors, on Doppler ultrasound, observe a significant increase in the flow in the fallopian tube, linked to the trophoblastic invasion allowing the diagnosis of EP [14]. Tubal localization is predominant, this corroborates with data from the literature [15] [16]. We have highlighted a heterotopic pregnancy case combining an intrauterine pregnancy and an ectopic pregnancy; some authors also report twins, and bilateral EPs [15].

Despite the fact that we were able to achieve $84.6 \%$ of blood transfusion, the immediate postoperative outcomes are complicated by anemia, which proves that there is insufficient supply of labile blood products, confirming with difficulties in supplying blood products in our workplace already noted in a previous study in the same department [12].

Some authors adopt expectation in the management and report $9 \%$ to $26 \%$ of EPs who spontaneously heal [17]. We have not made any expectations. Indeed, these indications are limited to a beta-hcg level of less than $1000 \mathrm{IU} / \mathrm{ml}$, an asymptomatic, hemodynamic and stable hematocrit EP with no ultrasound examination of hemoperitoneum and ovular sac. In Africa in general, care is provided at the final stage of cataclysmic rupture; there are several factors that delay diagnosis: poverty of the population, low level of education, low attendance at health facilities and low literacy rate.

However, medical treatment with methotrexate was used in only 3 cases. Some authors report that it is effective in $82.4 \%$ of cases if the inclusion criteria are strictly respected. It is recommended to use it intramuscularly as a single injection at a dose of $1 \mathrm{mg} / \mathrm{kg}$ or $50 \mathrm{mg} / \mathrm{m}^{2}$ body surface area, renewable a few days later at the same dose [18]. The success of treatment is limited by patient compliance and the demanding nature of follow-up [19]. According to some authors, in the event of a persistent undetermined localized pregnancy after more than 10 days in an asymptomatic woman and/or with an hcg level greater than $2000 \mathrm{UI} / \mathrm{l}$, methotrexate treatment is an option [20]. Methotrexate treatment does not alter fertility; it is less effective than conservative surgical treatment (salpingotomy) with the same recurrence rate, and the same intrauterine pregnancy rate regardless of the treatment chosen [21]. Conservative treatment has a risk of trophoblast persistence ranging from $3 \%$ to $20 \%$ [22], requiring monitoring by weekly dosing of b-hcg. 
The surgical approach of the EP today is laparoscopic. Laparotomy may be indicated in the event of simultaneous contraindications to medical treatment (criteria not met, contraindications to methotrexate) and laparoscopy (very adherent pelvis, very important hemoperitoneum). The choice between laparotomy and laparoscopy depends mainly on the woman's hemodynamic state, in the absence of any sign of shock, laparoscopy is preferred [23].

We only performed $23.1 \%$ laparoscopy, due to the patients' condition and the surgeons' ability to control this approach. Diagnostic laparoscopy remains the preferred examination for confirmation of diagnosis; it also offers the advantage of being able to make an inventory of associated lesions and to apply surgical treatment or in situ injection of methotrexate [24]. This surgical approach is contraindicated in the case of significant hemoperitoneum greater than two litres, or retrouterinehematocele. It can be applied in all procedures performed by conventional laparotomy provided that adequate equipment and trained operators are available. Laparoscopy offers the advantage of a short hospital stay and lower adhesive sequelae, but does not exempt biological monitoring in the case of conservative treatment because of $5 \%$ in relation to the trophoblastic tissue left in place [25]. The new diagnostic and therapeutic treatments are doubtful as to the practice of radical or conservative treatment, and in the case of conservative treatment, the choice between laparoscopy and medical treatment [15]. Thus, the concept of the degree of activity of the EP was born [16], to improve the therapeutic strategy by proposing therapeutic abstention for very low active EPs (b-hcg < $1500 \mathrm{UI} / \mathrm{l})$; methotrexate treatment for low active EPs (b-hcg < $5000 \mathrm{UI} / \mathrm{l})$ and surgical treatment by salpingotomy or Salpingectomy for active EPs. No significant differences were noted with regard to the subsequent prognosis of fertility regardless of the treatment option [16]. Due to the condition of the homolateral tube, often very damaged, with only $34.3 \%$ of good quality contralateral tubes, despite the desire for motherhood we practiced radical treatment at $92.6 \%$. Some authors propose Salpingectomy only in women who no longer wish to become pregnant, in the event of a tubal explosion, a very pathological tube, a tubal plasty or a recurrence of EP on the same tube [25]. In the case of conservative treatment (Salpingotomy), the beta-hcg level should be monitored from day 2 until complete negativation [25]. In most African countries, therapeutic abstention or medical treatment of the EP is rare because of late diagnosis and often surgery is the only therapeutic option [3] [4] [5] [11] [12] [26]. It is therefore a fairly significant therapeutic advance, we have not noted any cases of maternal death attributable to the EP, indeed in some developed countries, the EP no longer engages the vital prognosis of the pregnant woman, the psychological management of treated women becomes a major issue [1].

\section{Conclusion}

In Africa, the practice of medical treatment in the treatment of EP and the use of the coeliosurgery approach prove that early diagnosis of EP is possible. In order 
to perpetuate the updating of therapeutic methods in our workplaces, the popularization of the coeliosurgery approach, the maintenance of surgical equipment and the regularity of inputs should be absolutely imperative.

\section{Conflicts of Interest}

The authors declare no conflicts of interest regarding the publication of this paper.

\section{References}

[1] Bouyer, J. (2003) Epidemiology of Ectopic Pregnancy: Incidence, Risk Factors and Consequences. Journal of Gynecology Obstetrics and Human Reproduction, 325, 8-17.

[2] Diallo, B. (2002) The Place of Ultrasound in the Diagnosis of Ectopic Pregnancy in the Department of Gynaecology and Obstetrics at the Ignace Donka National Hospital, University Hospital of Conakry. Thesis Doctorate of Medicine.

[3] Buambo Bananga, S.F., Oyéré Moké, P., Babiessa, F., Gnékoumou, L.A., Nkihouabonga, G. and Ekoundzola, J.R. (2010) Ectopic Pregnancy (GEU). 139 Case Studies Collected at the University Hospital Centre of Brazzaville. Medecine d Afrique Noire, 5705, 259-264.

[4] Méyé, J.F., Sima-Zué, A., Sima Olé, B., Kendjo, E. and Engogah-Beka (2002) Current Ectopic Pregnancy Aspets in Libreville (Gabon): 153 Cases. Cahiers d Etudes et de Recherches Francophonel Santé, 12, 405-408.

[5] Yandza, M.C., Nguembi, E., Goddot, M., Ngbalé, R., et al. (2003) Epidemiological and Clinical Aspects of 116 Cases of Ectopic Pregnancy at Bangui Community Hospital. Médecine d' Afrique Noire, 50, 405-412.

[6] Report of Maternal, Neonatal, Infant and Child/Youth Deaths in Congo in 2016, National Observatory of Maternal, Neonatal and Child Deaths, WHO.

[7] Second Congolese Household Survey for Poverty Monitoring and Evaluation (ECOM 2011), Ministry of Economy, Planning, Spatial Planning and Integration. Analysis Report of the Quibb Component February 2012.

[8] Management of Ectopic Pregnancy. Recommendations for Clinical Practice CNGOF 2003.

[9] Murney, H., Baakdah, H., Bardell, T. and Tullaud, T. (2005) Diagnosis and Treatment of Ectopic Pregnancy. CMAJ, 173, 905-912.

https://doi.org/10.1503/cmaj.050222

[10] Condous, G., Emeka, O. and Bourne, T. (2004) The Management of Ectopic Pregnancies and Pregnancies of Unknown Location. Gynecological Surgery, 1, 81-86. https://doi.org/10.1007/s10397-004-0013-4

[11] Kenfack, B., Noubom, M., Bongoe, A., Atemkeng Tsatedem, F., Ngono, M., Nguenfack Tsangue, G. and Mboudou, E. (2012) Ectopic Pregnancy in a Semi-Rural Region of Africa: Epidemiological, Clinical and Therapeutic Aspects of a Series of 74 Cases Treated at Sangmelima District Hospital in Southern Cameroon. Pan-African Journal, 13, 71 .

[12] Dohbit, J.S., Foumane, P., Kapche, M.D., Mboudou, E.T., Doumbe, M. and Doh, A.S. (2010) Ectopic Pregnancy at the Bafoussam Regional Hospital. Epidemiological, Clinical and Therapeutic Aspects. Clinics in Mother and Child Health, 7, 1-4. https://doi.org/10.4303/cmch/C101977 
[13] Abdelaziz, B. (2001) Ectopic Pregnancy. These Medicine FMP.

[14] Dupuis, O., Comagua, O., Benifla, J.L., Batallan, A., Dhainault-Renolleau, C. and Madelenat, P. (2009) Ectopic Pregnancy EMC 5-032-A30.

[15] Gervaise, A. and Fernandez, H. (2010) Diagnostic and Therapeutic Management of Ectopic Pregnancies. Journal de Gynécologie Obstétrique et Biologie de la Reproduction, 39, 17-24. https://doi.org/10.1016/j.jgyn.2010.02.013

[16] Ramanah, R., Marguier, I., Mottet, N., Magnin, C. and Riethmuller (2018) EMC 5-032 A-30.

[17] Rutala, M. and Mukinen, J. (1997) Tubal Patency and Fertility out Come after Expectant Management of Ectopic Pregnancy. Fertility and Sterility, 68, 1043-1046. https://doi.org/10.1016/S0015-0282(97)00414-7

[18] Hedon, B., Manet, H., Fauconnier, A., Minoum, C., Lagarde, L., et al. (2014) Outside. Inventory and Expertise on the Use of MA in Gynaecology: CNGOF Work. 38th National Day, 717-734.

[19] Gajewska, M., Kaminski, P., Wielgos, M., Szymusilk, I., Zimmer, M., Mazonowska, N., et al. (2008) Laparoscopic Management of Ectopic Pregnancy. Neuro Enocrinology Letters, 29, 267-271.

[20] Marret, H., Fauconnier, A., Dubernard, G., Misme, H., Lagarce, L., Lesavre, M., et al. (2015) Inventory and Expertise of the Use of Methotrexate in Obstetrical Gynecology outside the MA: Work of the CNGOF. Journal de Gynécologie Obstétrique et Biologie de la Reproduction, 44, 230-236.

[21] Lesavre, M., Curinier, S., Capmas, P., Ribischong, B. and Fernandez, H. (2015) Use of Methotrexate in Tubal EPs. Journal de Gynécologie Obstétrique et Biologie de la Reproduction, 44, 212-219.

[22] Yao, M. and Tulundi, T. (1997) Current Status of Chirurgical and Non-Chirurgical Management of Ectopic Pregnancy. Fertility and Sterility, 67, 421-433. https://doi.org/10.1016/S0015-0282(97)80064-7

[23] Delmas, M., Nasredine, A., Gondry, J., Boulanger, J. and Lourdel, E. (2003) Medical Treatment of EP with Methotrexate. Amien's Maternity Experience. About 92 Cases. Journal de Gynécologie Obstétrique et Biologie de la Reproduction, 32, 3.

[24] Alami, M.H. and Tazi, Z. (1998) Ectopic Pregnancy (EP) about 25 Cases: Therapeutic Aspects and Literature Review. Maghreb Medicine, 70, 23-27.

[25] Mervel, P., Lourdel, E., Gagneur, O., Nasreddine, A., Brzakowsky, et al. (2010) Surgical Treatment: Techniques, Advantages and Disadvantages. Excerpt from the CNGOF 2010 Medical Gynecology Updates.

[26] Telly, S., Diallo, Y., Touré, A., Diallo, B., Baldé, A.A., Hyjazy, Y. and Diallo, M.S. (2009) Management of Ectopic Pregnancy in Conakry (Guinea). Médecine Tropicale, $69,565-568$. 